\title{
A sustainability comparative assessment of Tunisian organic and conventional olive growing systems based on the AHP methodology ${ }^{1}$
}

\author{
Saker Ben Abdallah*, Saida Elfkih**, Carlos Parra-LóPez ${ }^{\star \star *}$ \\ DOI: $10.30682 / \mathrm{nm} 1803 \mathrm{e}$ \\ JEL Codes: Q19, Q55, Q58
}

\begin{abstract}
This work aims to assess, in a comparative way, the sustainability of organic and conventional olive growing systems in the Sfax region (Tunisia). This assessment will be undertaken based on I) a multidimensional perspective considering the three classical dimensions of sustainability - environmental, economic and socio-territorial - and II) on an experts' knowledge approach selecting the adequate criteria of sustainability to compare both systems. The Analytic Hierarchy Process methodology (AHP) was applied as the adequate framework to fulfil the study objectives based on a survey directed with a panel of 20 Experts. Results suggest the need to reinforce the economic performance of organic olive growing production system through political strategies focusing on I) the improvement of the productivity by the implementation of good practices II) the increase of the demand of organic products in the local market, essentially by the improvement of the consumer's purchase capacity and III) the adoption of a strategic plan to explore new markets.
\end{abstract}

Keywords: Criteria, Experts'knowledge, Multidimensional perspective, Sfax.

\section{Introduction}

Nowadays, it is widely accepted by the scientific community, decision makers and farmers that modern agriculture must meet new challenges such as the production of healthy food, adaptation to climate change, protection of natural resources, and conservation of landscape (Carof et al., 2013). These challenges point out the multifunctional role of agriculture and the sustainability concept. In this context, multifunctionality refers to the multiple functions that society assigns to and demands from agriculture. The preservation of a multifunctional agriculture may lead to more sustainable growing systems. Thus, sustainability is a multi-dimensional and multi-criteria concept that entails a set of economic, social, and environmental issues (Elfkih et al., 2012).

For many decades, conventional agriculture has imposed many negative externalities upon

\footnotetext{
1 The two first authors have equally contributed to this work.

* Department of Agricultural Economics, University of Córdoba. Campus universitario de Rabanales. Córdoba (España). ** Department of Sustainability of olive tree growing systems and product quality. Sfax, Olive Tree Institute. Tunisia. *** Department of Agricultural Economics and Sociology. Institute of Agricultural and Fisheries Research and Training (IFAPA). Granada, Spain.

Corresponding author: sakerbenabdallah@yahoo.fr.
} 
society, through land and water resources overuse, biodiversity loss, erosion, non controlled use of pesticides, and assorted other problems. In contrast to this system, organic agriculture represents a deliberate attempt to make the best sustainable use of natural resources. In fact, the negative effects associated with intensive systems were the main motivations of an increasing social demand for more sustainable production systems. This has led to a big expansion of the international organic market, even in countries that were suppliers for developed countries (Callieris et al., 2016), making of organic farming a more attractive activity to producers. In this context, sustainability can be closely linked to organic farming - one of the most viable growing systems which has been rapidly extended in the past two decades in many countries (Rigby and Cáceres, 2001).

In Tunisia, organic farming is an activity that goes back to late $90 \mathrm{~s}$. In fact, specific interest was allocated to organic farming with the initiative of a group of motivated and innovative farmers and supported by political commitment. Thus, in 1999, a specific regulation was established setting rules governing production and organic farming control (Tunisian Regulation $\mathrm{N}^{\circ}$ 99-30 of 5 April 1999). The Tunisian system of production and control measures for organic production are recognized as equivalent to those laid down in Regulation (EC) No 834/2007 ((EC) No 537/2009). In Tunisia, organic farming is a very interesting activity covering a surface of 198.000 ha in 2015. Olive growing is the main organic agriculture activity with 148.000 ha representing almost $75 \%$ of total national organic area. Sfax is one of the most important olive growing Tunisian regions retaining $23 \%$ of national olive oil production which is mostly exploited under the conventional system. The conventional production system has many adverse environmental effects, especially the degradation of soil organic matter in the Sfax region (Rivals, 1961). Sfax is also one of the most organic olive oil producers with 5872 tons representing the $22 \%$ of the overall national production of organic olive oil for the period 2011-2015 (Data of the Tunisian Ministry of Agriculture).
Despite the positive evolution of organic farming, many questions were raised about the overall sustainability of these production systems: highlighting possible conflicts between the optimisation of economic profitability, environment protection and the improvement of social wellbeing. Bringing about such a balance requires optimizing a range of agronomic, environmental and socio-economic outcomes from agricultural systems (Kanter et al., 2016). In fact, many researchers consider that research on sustainability assessment in agriculture has so far poorly addressed multi-functionality in agriculture and has favoured the ecological aspect of sustainability instead of aiming at a balance between the ecological, economic and social dimensions, and neglected the knowledge of utilizing the results of assessments to achieve their implementation (Binder et al., 2010; Bezlepkina et al., 2011). For this reason, starting a study considering the three dimensions of sustainability seems to be very interesting to design more mitigation-oriented strategies.

In the case of olive growing systems, a few studies have followed a more explicitly holistic approach, such as those of Parra-López et al. (2008), Laajimi and Ben Nasr (2009), GómezLimón and Arriaza-Balmón (2011), Elfkih et al. (2012), and Carmona-Torres et al. (2014). These researches reveal the specificities of each studied case. So, there is not one farm sustainability model which can be applied to all the cases. Therefore, each local farming situation involves a set of sustainability indicators and involves an adapted theoretical framework.

To assess the sustainability of particular agricultural systems, a multi-criteria analysis can be implemented. In all complex multi-criteria approaches, evaluating sustainability poses problems of high complexity, uncertainty and risk. The AHP methodology is proposed as an adequate multi-criteria framework to mitigate weaknesses and disadvantages of other indicators' methods such as Farm Sustainability Indicators method (IDEA). Thus, the AHP method has the advantage of providing an aggregated overall sustainability whereas the overall sustainability in the IDEA method is based on the rule of key constraint (the lowest value of the 
three sustainability scales: economic, social and environmental is used as the final numerical sustainability) (Elfkih et al., 2012). Indeed, in this study, the AHP method seems to be one of the most adapted theoretical frameworks and one of the most powerful methods providing adequate responses to the multifunctionality and the sustainability evaluation of agricultural production systems for at least two reasons: I) AHP is a discrete multi-criteria analysis method dealing with the complex decision- making of multiple agents in a context of high conflict of interests as this case study; II) AHP allows the achievement of an overall aggregated sustainability evaluation.

The main purpose of this paper is to assess the sustainability of both organic and conventional olive growing systems in the Sfax region through the AHP method. To fulfill this objective, the paper will be organized as follows. The next section presents the material and methods with a special focus on the implemented AHP model. The third section includes a presentation and a discussion of the main results obtained. Finally, conclusions and recommendations are highlighted.

\section{Material and methods}

This paper aims to assess the sustainability and the current state of both organic and conventional olive growing systems in the Sfax region by prioritizing the olive production methods established by a sample of experts using AHP. Therefore, the results could provide a scientific basis for endorsing institutional support for the promotion and implementation of a farming system with a greater value for society, both for present and future generations.

To fulfil the outlined objectives, a well-defined approach is needed to assess sustainability and to structure the problem: from the setting of the goal to the sensitivity analysis. Thus, we distil agricultural sustainability analysis into four steps: 1) Structuring the decision problem and identifying the specific-context of needed criteria to assess agricultural sustainability; 2) Selecting the method for generating score of criteria and alternatives across different dimensions; 3) Assignment and comparison of criteria values with decision-makers (experts' knowledge); 4) A sensitivity analysis for delimiting the most sensitive farming functions, i.e. those with the highest potential to affect the sustainability of olive growing at farm-level.

The selection of sustainability criteria in the current study has been founded mainly on experts' knowledge of olive growing farms in the Sfax region. In fact, experts were consulted in both steps: the selection of criteria and the evaluation of the two systems. Thus, experts are acquainted with specific characteristics of the region (socio-economic, agronomic sectors and edapho-climatic conditions etc.), and they have enough expertise to resolve the quantification complexity of the environmental and socio-economic impact of the two systems through the AHP method.

\subsection{The study area}

The olive growing area in the Sfax region is currently estimated at about 340.700 hectares, representing approximately $19,5 \%$ of the national total area. It has contributed to approximately $23 \%$ of the national production of olive oil during the past decade (2006-2015) with an average estimated at 45.000 tons of olive oil (Ben Abdallah, 2015). Sfax is also the most important Tunisian organic olive growing region in surface area and production. The olive growing sector is the locomotive of organic farming in the Sfax region with 22.300 ha (about $18 \%$ of organic olive growing area in Tunisia) (Statistics of the Tunisian Agricultural Ministry). Despite this positive growth and favorable conditions, only a small share of the total agricultural land is under organic agriculture $(2,1 \%)$. In this perspective, it is important to test the highest multifunctional value of the alternative farming systems compared to the conventional one.

\subsection{Research method: AHP methodology}

The AHP (Saaty, 1980) is an intuitively easy method for the practical resolution of complex decision-making problems that involves the prioritization of potential alternate solutions. Several papers have compiled the AHP success stories in very different fields (Ishizaka and Labib, 
2009). In regard to the sustainability assessment field, Cinelli et al. (2014) showed that Multi Attribute Utility Theory (MAUT) and AHP are fairly simple to understand and have good software support compared to other methods such as: Preference Ranking Organisation Method for Enrichment Evaluations (PROMETHEE), Elimination and Choice Expressing Reality (ELECTRE) and Dominance-based Rough Set Approach (DRSA).

The software widely used in AHP applications is the "Expert Choice". The AHP and expert choice softwares engage decision makers in structuring a decision as a multi-level hierarchical model (AHP model), proceeding from the goal to objectives to sub-objectives down to the most basic elements of the problem (alternatives). Decision makers, then, make simple pair-wise comparison judgments between elements for each level of the hierarchy (objectives, sub-objectives) for their importance with respect to each of the elements in a higher stratum to arrive at alternatives. These comparisons are used to obtain the weights or priorities of importance of the decision elements and performance of alternatives. This process ends with the synthesis to determine the best alternative.

In our case study, the decision-makers' panel was of 20 experts specialized on olive growing systems from the Sfax region. The experts were divided into two groups according to the personal knowledge of each production system in the following way: 10 experts specialized in the conventional olive system and 10 experts specialized in the organic olive system. It must be pointed out that these participants have a large experience in both study fields (organic and conventional) but they were divided according to their preferences and their most important expertise areas. Listed by profession, 8 were private farmers-engineers (olive growers), 2 researchers from public research centers, 7 practitioners-engineers of the olive growing sector in State Lands and 3 government employees.

Relying on the experts, judgement has limits, mainly due to subjectivity, and divergence of opinions may emerge. To deal with this issue and evaluate its effect on the results obtained, a "Relative Global Agreement index" (RGA index) was calculated. It was developed by a researchers group from the Department of Agricultural Economics and Sociology of the Institute of Agricultural and Fisheries Research and Training of Granada (Spain). This index measures the consensus gradient between the opinions of two stakeholder groups involved in the decision- making process (Parra-López et al., 2007).

The steps of AHP, from building the decision model to giving alternatives' priorities, are as shown below.

\subsubsection{The AHP model}

To fulfil the study objectives; the selection of evaluation sub-criteria in each sustainability dimension (economic, socio-territorial and environmental) were based on: (I) an accurate revision of the scientific literature related to the context of sustainable development specific to the situation of the olive-growing sector in Tunisia and particularly in the Sfax region; and (II) a panel of experts on conventional and organic olive growing specialists was selected to act as the decision group. The decision group formulates the AHP decision hierarchy based on the selection of the most relevant criteria and indicators. These criteria ought to be the more significant: in revealing the socio-economic and environmental strengths and/or weaknesses of each system and to establish, if needed, an extension program for the diffusion of innovative olive production methods. Figure 1 depicts the hierarchical model for selection of olive-growing production systems. The following is the meaning in short of the sub-objectives (sub-criteria):

Economic objectives. I.1. Income: This refers to the financial results of olive growing. I.2. Income Stability: It is related to product sustainability in the medium-long term. I.3. Financial autonomy: It is related to economic independence with respect to debts. I.4. Encouragement by subsidies: This criterion reflects the rate of the farmer's knowledge of the existing subsidies for agriculture and the State encouragement provided to each production system. I.5. Market accessibility: It relates market accessibility and valorization through short marketing circuit.

Socio-territorial objectives. II.1. Contribution to employment creation: Direct and indirect jobs. 
Figure 1 - The AHP model for selecting of the most sustainable olive growing system.

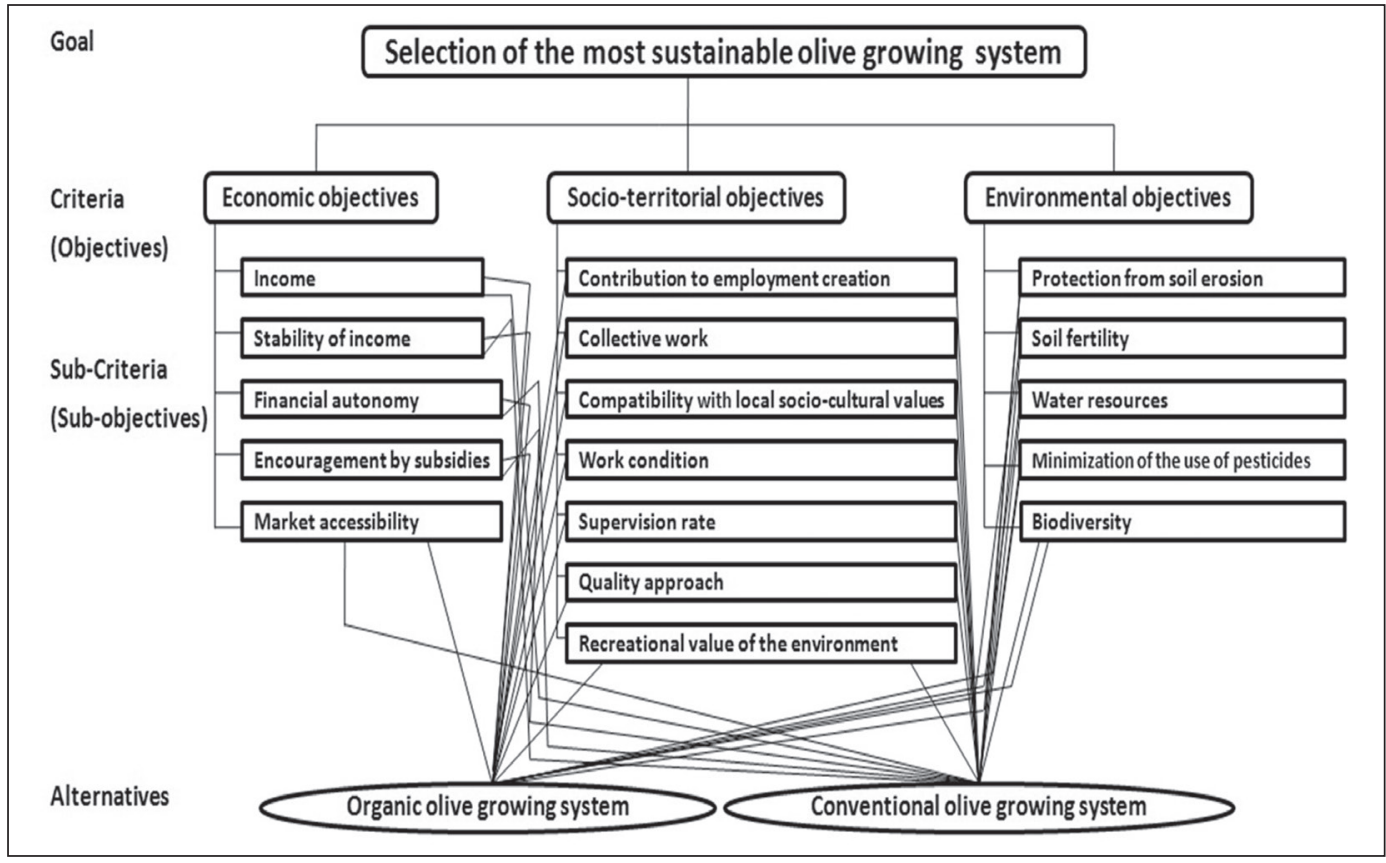

II.2. Collective work: Participation in collective work developed within the territory. This entails solidarity, better efficiency, saving of scale and synergies, etc. II.3. Compatibility with local socio-cultural values: Compatibility of the farming practices with producers' traditional values and the conformity of generated products with consumers' culinary habits. II.4. Work conditions: Work health status (hygiene) and good working conditions through: decent salary, social security and involvement in training. II.5. Supervision rate: This reflects the interest of the farmer to improve the farm through access to information. II.6. Quality approach: Implementation of quality labels for food officially recognized. II.7. Recreational value of the environment: Multi-activity associated to agricultural systems and related to leisure activities.

Environmental objectives. III.1. Protection from soil erosion: Preserving the ground by limiting the effect of water or wind erosion and/or ensuring the presence of a permanent plant cover. III.2. Soil fertility: It is related to the management of organic matter and nitrogen fertilization. III.3. Water resources: Good management of this resource by farmers under the arid climate of the region. III.4. Minimization of the use of pesticides: Reducing the use of chemicals treatments. III.5. Biodiversity: The Diversity of plants, animals and genetic varieties of olive-trees can contribute to the economic income, minimize climatic or health risks, increase soil fertility and protect the soil from erosion.

\subsubsection{Pair-wise comparison and priorities}

Once the model had been built, the next step was to evaluate the elements by making a Pairwise Comparison (PC). At each level of the hierarchy, experts had individually performed a PC between two elements $(i, j)$ with respect to another element in the level above. PC was carried out through the model to establish priorities while respecting the rating scale proposed by AHP (Figure 2). Expert Choice has three modes of PC assessment: verbal, graphical and numerical. Numerical judgments were made using a nine-point scale (Figure 2), which represents how many times one element is more important than another (www.expertchoice.com). 
Figure 2 - The fundamental verbal and numerical scale of pair wise-comparison in AHP.

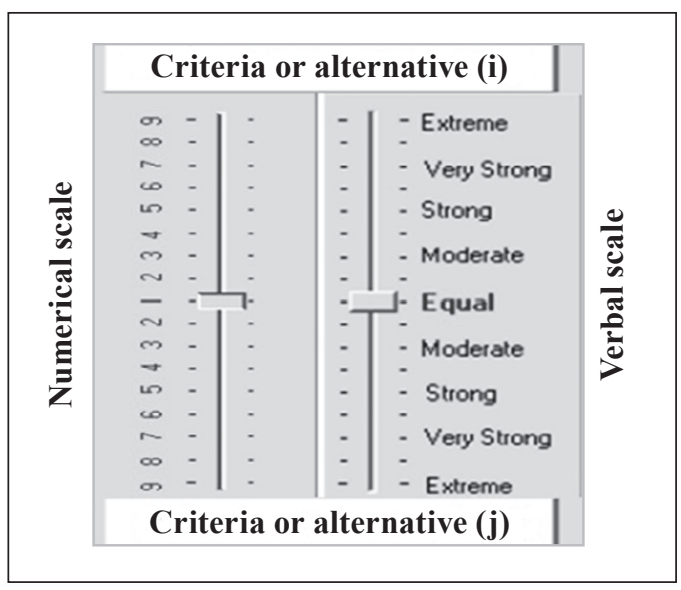

In the following sections, a node is an element of the hierarchy on which other sub-elements depend.

\subsubsection{Local priorities}

The local priorities or weights $\left(p_{\mathrm{L}}\right)$ of each node's sub-elements must be assessed and then standardized, i.e., they must accomplish:

$$
\sum_{i=1}^{n} p \mathrm{~L}(\mathrm{i})=1
$$

These weights or priorities may be evaluated on the basis of PC of these sub-elements $\left(p_{\mathrm{L}(\mathrm{i})} /\right.$ $\left.p_{\mathrm{L}(\mathrm{j})}\right)$ with respect to the satisfaction of the node on which they depend. On the basis of these ratios, it is possible to construct a comparison matrix (Â) with elements: $\mathrm{a}_{\mathrm{i}, \mathrm{j}}=p_{\mathrm{L}(\mathrm{i})} / p_{\mathrm{L}(\mathrm{j})}$ :

$$
\hat{\mathbf{A}}=\left(\begin{array}{ccccc}
1 & \mathrm{pL}(1) / \mathrm{pL}(2) & \mathrm{pL}(1) / \omega \mathrm{L}(3) & \ldots & \mathrm{pL}(1) / \mathrm{pL}(\mathrm{n}) \\
& 1 & \mathrm{pL}(2) / \omega \mathrm{L}(3) & \ldots & \mathrm{pL}(2) / \mathrm{pL}(\mathrm{n}) \\
& & 1 & \ldots & \mathrm{pL}(3) / \mathrm{pL}(\mathrm{n}) \\
\text { inverse } & \ldots & \ldots & \ldots & \ldots .
\end{array}\right)
$$

It is a positive reciprocal matrix having a series of important properties: (I) It is square (order $\mathrm{n} * \mathrm{n})$; (II) All diagonal elements hold the value 1; (III) Their elements accomplish: $a_{\mathrm{i}, \mathrm{j}}=1 / \mathrm{a}_{\mathrm{j}, \mathrm{i}}, \forall_{\mathrm{i}, \mathrm{j}}$; being $\mathrm{a}_{\mathrm{i}, \mathrm{j}}=\mathrm{p}_{\mathrm{L}(\mathrm{i})} / \mathrm{p}_{\mathrm{L}(\mathrm{j})}$ (Saaty, 1994; Forman and Selly, 2001) The local priorities of the sub-elements depending on the node may be calculated by the resolution of the eigenvector of the equation systems:

$$
\hat{\mathrm{A}} * \mathrm{p}_{\mathrm{L}}=\lambda * \mathrm{p}_{\mathrm{L}}
$$

Where $p_{L}$ is the column vector of local priorities and $\lambda$ is the maximum Eigen value. These priorities have a natural ratio (Saaty, 2001). The inconsistency of the judgment matrix can be proven by the indicators $\lambda \geq n$ and the difference $\lambda-\mathrm{n}$ where $\mathrm{n}$ is the number of comparative elements. A consistency ratio of 0.1 is considered the acceptable upper limit.

\subsubsection{Synthesis of priorities}

Alternatives may be ranked according to their priorities (or performance) with respect to the goal (global priorities, $\mathrm{p}_{\mathrm{G}}$ ) or any intermediate node of the decision hierarchy (final priorities, $\mathrm{p}_{\mathrm{F}}$ ). The Final priorities of alternatives (conventional and organic olive growing systems) for a given node of the AHP model (for example the "economic objectives") can be calculated by weighted addition based on the local priorities of the elements depending on it, according to:

$$
\mathrm{p}_{\mathrm{F}(\mathrm{AK})}=\sum_{i=1}^{I} \mathrm{pL}\left(\frac{\mathrm{AK}}{\mathrm{i}}\right) * \mathrm{pL}(\mathrm{so}(\mathrm{i}))
$$

Where $\mathrm{p}_{\mathrm{F}(\mathrm{Ak})}$ is the final priority of the alternative $K\left(\mathrm{~A}_{\mathrm{k}}\right.$ being the conventional or organic farming system); $p_{\mathrm{L}(\mathrm{Ak} / \mathrm{i})}$ is the local priority of the $\mathrm{k}$ alternative with respect to the i sub-objective depending on the main criterion. $\mathrm{p}_{\mathrm{L}(\mathrm{so}(\mathrm{i}))}$ is the local priority of the $\mathrm{i}$ sub-objective with respect to the main criterion, and I is the number of sub-objectives depending on the criterion (Saaty, 1994). The global priorities $\left(\mathrm{p}_{\mathrm{G}}\right)$ can be calculated similarly on the basis of all local priorities of sub-objectives and alternatives depending on the goal.

\subsubsection{Agreement measurement: RGA index}

As previously mentioned, RGA index measures the consensus gradient between experts' opinions. In this case, two groups are involved: one group is specialized in the organic system and the other in the conventional one. Relative Global Agreement index is a measure of the convergence of opinions of individual groups with respect to the mean of all the groups. The Relative Global Agreement index is a node that measures the importance of consensus among all groups. 
Thus, the consensus is increasingly important as the RGA index acquires greater values. The Relative Global Agreement index is defined as:

$$
\mathrm{RGA}=\frac{1}{\frac{\sum_{\nabla \mathrm{g}}\left(\frac{\sum_{i=1}^{n} \frac{\mathrm{pL}(\mathrm{i}, \mathrm{g}-\mathrm{pL}(\mathrm{i}), \mathrm{m}}{\mathrm{pL}(\mathrm{i}), \mathrm{m}}}{n}\right)}{G}}
$$

where $\mathrm{G}$ is the number of decision groups, $\mathrm{g}$ is a particular decision group, $\mathrm{p}_{\mathrm{L}(\mathrm{i}), \mathrm{g}}$ is the mean local priority of the $\mathrm{i}$ element with respect to the node for the g group, $p_{L(i)}, m$ is the mean local priority of the $\mathrm{i}$ element for the $\mathrm{G}$ groups and $\mathrm{n}$ is the number of child sub-nodes or node alternatives.

RGA index must be calculated for both the local priorities of elements (nodes and alternatives) and the final and global priorities of the alternatives. RGA index for the final priorities of alternatives, at a particular node, is simply calculated by substituting $p_{L}$ by either $p_{G}$ or $p_{F}$, respectively, in Eq (5). Once RGA is calculated for all the nodes, agreement degrees can be segmented in low, medium, and high. The agreement degree's limits are the percentiles $1 / 3$ and $2 / 3$ : the first third are the nodes with a low agreement gradient, the next, those with a medium agreement gradient and the last third, those with a high agreement gradient (Table 1).
Table 1 - Agreement degrees' segments.

\begin{tabular}{|l|l|}
\hline Agreement degree & \multicolumn{1}{|c|}{$R G A$} \\
\hline Low & RGA $\leq$ Percentile $1 / 3$ \\
\hline Medium & $\begin{array}{l}\text { Percentile } 1 / 3<\text { RGA } \leq \\
\text { Percentile } 2 / 3\end{array}$ \\
\hline High & Percentile $2 / 3<$ RGA \\
\hline
\end{tabular}

It is very important to note that these limits are exclusive and different for each AHP model. They are used to classify the agreement level of each node in relative terms, that is to say, in relation to the level of agreement of the remaining nodes of the estimated model.

\section{Results}

The figures mentioned in the following paragraphs show the mean opinions of both groups of experts. It summarizes the results of the relative priorities of the different criteria and sub-criteria at each level of the model ("Local priorities of nodes") as well as the relative performances of the organic and conventional olive farming systems in this region at each node ("Priorities of alternatives"). The inconsistency index also refers to the mean opinions. This is always below 0.10 for mean opinions as well as for each group and individual experts.
Goal: Global sustainability of olrve growing

I. Economic objectives (L: 480)

$\square$ (I.1) Income (L: ,239)

(I.2) Income stability (L: ,255)

(I.3) Financial autonomy (L: ,228)

(L.4) Encouragement by subsidies (L: ,044)

(L.5) Market accessibility $(\mathrm{L}:, 232)$

$\square$ II. Socio-territorial objectives (L: ,163)

$\square$ (II.1) Contribution to employment creation ( $\mathrm{L}:, 171)$

(ㅍ.2) Collective work (L: ,135)

(II.3) Compatibility with local socio-cultural values (L: ,053)

(ㅍ.4) Work conditions (L: ,238)

(II.5) Supervision rate (L: ,206)

$\square$ (ㅍ.6) Quality approach (L: ,118)

$\square$ (ㅍ.7) Recreational value of the environment ( $\mathrm{L}:, 078$ )

III. Environmental objectives: (L: ,357)

(III.1) Protection from soil erosion (L: ,187)

(III.2) Soil fertility (L: ,277)

(III.3) Water resources (L: ,345)

$\square$ (III.4) Minimization of the use of pesticides (L: ,046)

(III.5) Biodiversity (L: ,145)
Figure 3 - Local priorities of criteria and sub-criteria. 
Figure 4 - Performances of the olive systems in the goal.



\subsection{Comparative assessment of criteria and sub-criteria}

The local priorities of the three main criteria of the model (economic, socio-territorial and environmental) with respect to the goal show a slight difference being, in a decreasing order of importance: economic, environmental, and socio-territorial criteria $(0.480,0.357$ and 0.163$)$ (Figure 3). This reflects the current trend of olive growers in the Sfax region. They are neglecting the environmental and socio-territorial objectives of their activity, compared to the economic objectives. This same olive growers' behaviour was observed in previous studies in the Andalucia region (Spain) (Parra-López et al., 2008; Carmona-Torres et al., 2014).

\subsection{Comparative assessment of alternatives}

\subsubsection{Global sustainability}

According to the results shown in Figure 4, the organic olive-growing system is more globally sustainable according to the mean opinion of both groups of experts (Global priority $\left(\mathrm{p}_{\mathrm{G}}\right)=0.696$ ). This result is in agreement with previous studies comparing these two olive systems in the same study zone and from a multi-criteria point of view (Laajimi and Ben Nasr, 2009).

This result has important policy consequences. This is probably an approximation of the real "total economic value" of these olive-farming systems for society.

\subsubsection{Sustainability in the three dimensions}

Figure 5 indicates the priorities of the alternatives with respect to each objective and sub-objectives (economic sub-objectives, socio-territorial sub-objectives and environmental sub-objectives). The organic olive system sus- tainability is clearly superior to the conventional one in the three main objectives of the model and, therefore, at the overall level, as shown in the previous section. It must be pointed out that of the three analysed criteria, the environmental one shows the greatest difference in the performance of the two alternatives. However, the economic criterion presents less difference between both alternatives.

\section{Economic sub-criteria}

Regarding the performance of both farming systems in the economic sub-criteria ("Priorities of alternatives" Figure 5), organic olive growing has several advantages with respect to the conventional one, such as: (I) a better stability of the income; (II) an independence in the supply of inputs and a regular payment of debts (III); it is easier to sell organic olive oil in the local market, given its good reputation among Tunisian consumers, and this despite its sale as a conventional product in this market and the difficulties faced in the international market to commercialize the entire quantity produced. However, the average opinion of both groups of experts reveals that the conventional alternative entails a slightly higher income for farmers $(p=0.546)$ than that of the organic one (0.454). This result appears to be acceptable by considering the current situation of the organic product in Tunisia. Hence, according to Lampkin and Padel (1994), the income of organic farming in the short/medium term is lower than that of the conventional one. This is mainly related to (I) the higher production costs of the organic olive oil; (II) the price fluctuation of the organic olive-growing product being sometimes equal to that of the conventional one, and (III) according to Delate et al. (2003), farms with 
Figure 5 - Performances of the olive systems in the objectives and sub-objectives.

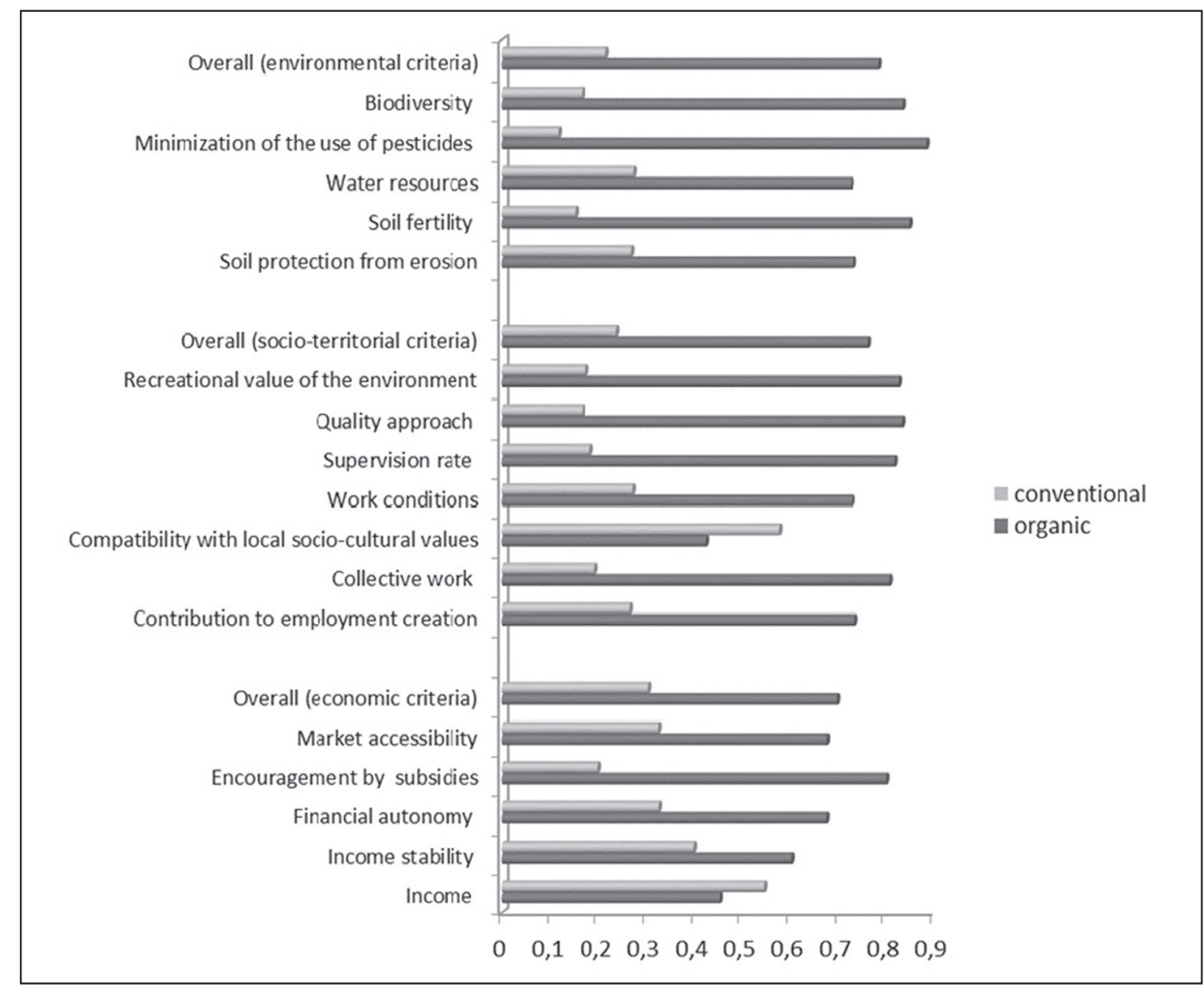

less fertility or inadequate expertise in organic practices may experience a longer "transitional effect" in which organic yields remain substantially lower than conventional yields.

The improvement of the economic situation of the organic production system being the most sustainable production method can be carried out through the encouragement of this sector by increasing subsidies, the implementation of a better strategy of integration in the sector and the organization of producers through cooperatives.

\section{Socio-territorial sub-criteria}

In terms of socio-territorial criteria (Figure 5), the organic olive growing system allows: more employment creation, a better product quality and a possible enhancement of the environment, thus contributing to the maintenance of space and landscapes. The organic system is more diversified, allowing exchanges between the agricultural and the territory, contributes to the creation not only of an economic value of both space and environment but also the preservation of many agricultural systems. In relation to the criterion "Compatibility with local socio-cultural values", the conventional alternative has a synthetic priority slightly higher than the organic alternative because I) from the producer's perspective, organic practices are more discordant with the farmers' practices, on the one hand, and II) from consumers' perspective, the lack of demand for organic products in the local market. According to the experts, the organic product is still sold with a specific consumers' category in the local market. These consumers still have a relatively high purchasing power. 
Figure 6 - Performance sensitivity graphics.

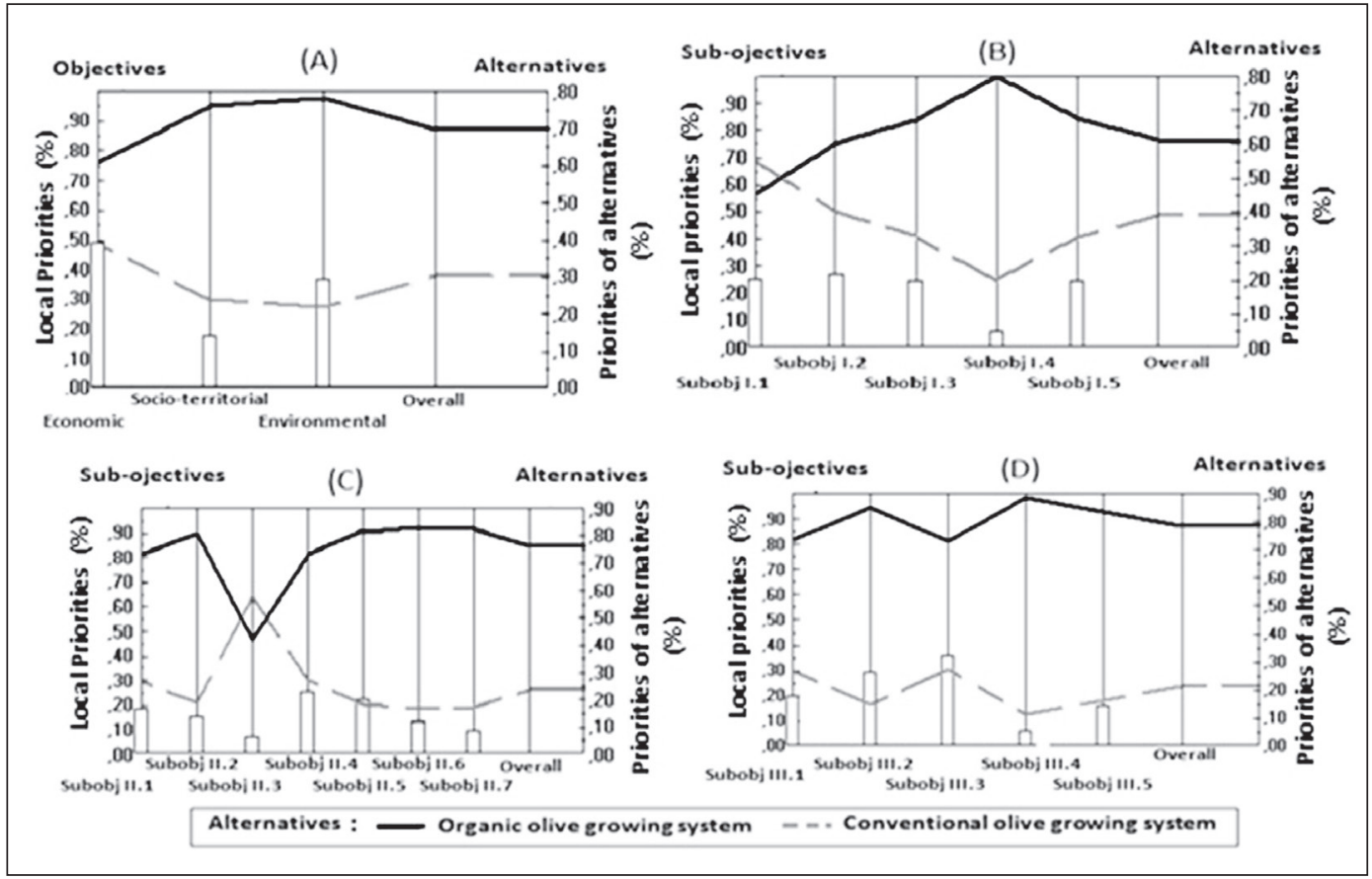

Note: Graphic (B) - Subobj I.1: Income; Subobj I.2: Income stability; Subobj I.3: Financial autonomy; Subobj I.4: Encouragement by subsidies; Subobj I.5: Market accessibility. Graphic (C) - Subobj II.1: Contribution to employment creation; Subobj II.2: Collective work; Subobj II.3: Compatibility with local socio-cultural values; Subobj II.4: Work conditions; Subobj II.5: Supervision rate; Subobj II.6: Quality approach; Subobj II.7: Recreational value of the environment. Graphic (D) - Subobj III.1: Protection from soil erosion; Subobj I.2: Soil fertility; Subobj I.3: Water resources; Subobj I.4: Minimization of the use of pesticides; Subobj I.5: Biodiversity.

\section{Environmental sub-criteria}

According to the experts, organic olive growing is the best environmental alternative (Figure 5 and Table 2). Moreover, it presents the greatest differences in performance when compared to the conventional alternative in the environmental sub-criteria. The overall environmental superiority of the organic system over the conventional one is in accordance with previous studies (Stolze et al., 2000; Hansen et al., 2001; Pacini et al., 2003, 2004; Parra-López et al., 2007; Laajimi and Ben Nasr, 2009; Tuomisto et al., 2012). By preserving soil fertility, the organic system can fight the degradation of the organic matter of soils in the Sfax region. Besides, the organic agricultural method, using green manure, allows farmers to enrich the soil with organic matter and to improve its capacity of water retention. The practical experience of most experts ( 6 are organic farmers) showed that the olive-tree was suited to the organic method under the edaphic-climatic conditions of this region. On the other hand, the diversity of the intercalary plantations of fruit trees strengthened the financial autonomy and the income stability in the organic system.

\subsection{Sensitivity analysis}

Sensitivity analysis is designated to examine the decision results (Figure 6 and Figure 7). The Expert Choice implementation of AHP provides four graphical sensitivity analysis modes: dynamic, gradient, performance and two-dimensional analysis. The ranking of alternatives can be changed by increasing or decreasing the importance of the criteria or sub-criteria (local priorities or weights). For this reason, the local priorities of the main criteria and sub-criteria are separately altered, simulating weights between $0 \%$ and $100 \%$ (note that the priorities of the other criteria change accord- 
Figure 7 - Performance sensitivity graphics in the economic and socio-territorial sub-objectives.

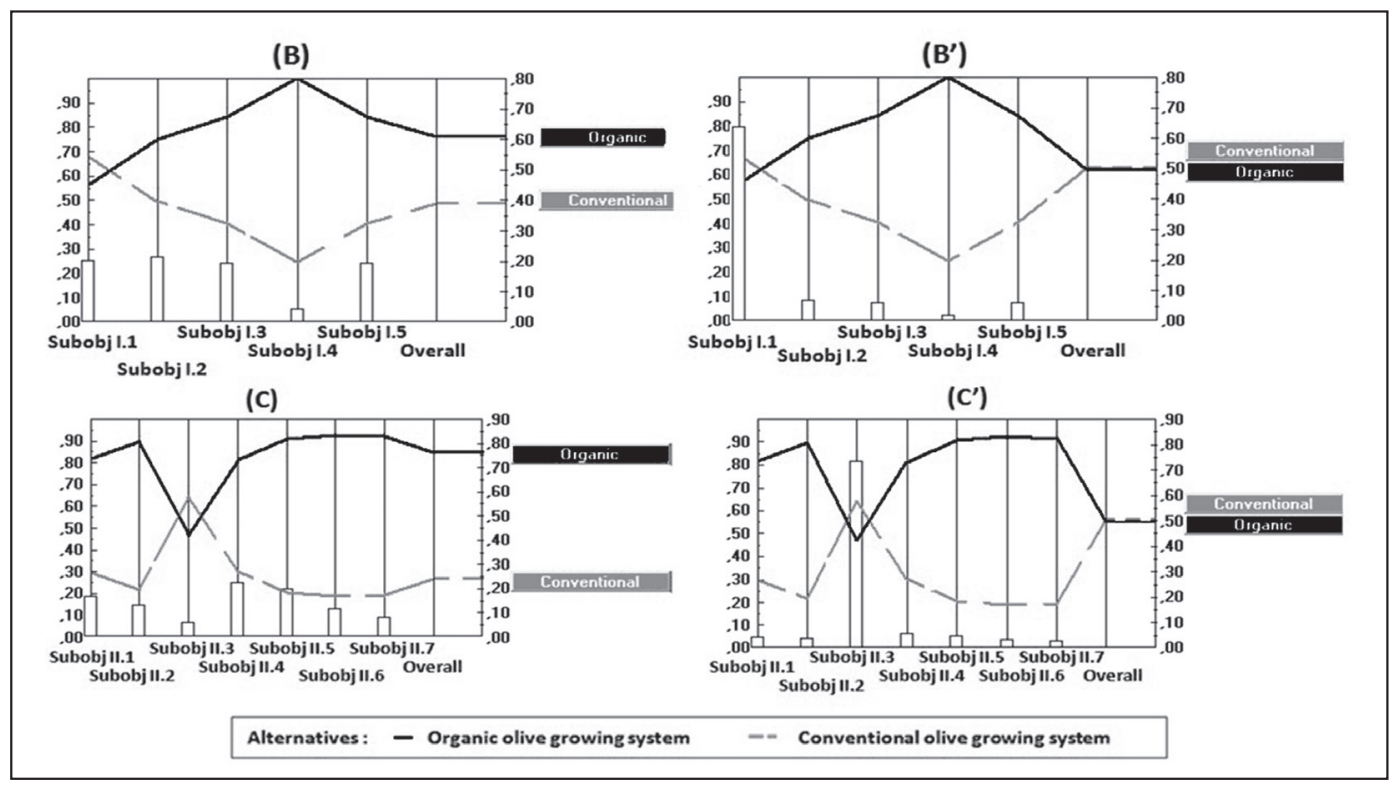

ingly, reflecting the relative nature of the weights, i.e., the total weights have to add up to $100 \%$ in this paper). Figure 6 shows the results before making any changes on local weights of criteria and sub-criteria (objectives and sub-objectives). The graphs (A, B, C, D) show successively: graph (A) - performances sensitivity of the olives systems in the three main objectives and Goal (Overall); graph (B) - performances sensitivity of the olives systems in the economic sub-criteria; graph (C) - performances sensitivity of the olives systems in the socio-territorial sub-criteria and (D) - performances sensitivity of the olives systems in the environmental sub-criteria. The change of the alternatives ranking overview was only in the graph (B and C). Therefore, two other graphs after the change were obtained (Figure 7) B' and C'. In the case of increasing: I) local priorities of sub-criteria "income" from 0.239 to 0.774 (Figure 7: B, B'), II) local priorities of sub-criteria "Compatibility with local socio-cultural values" from 0.053 to 0.786 (Figure 7: C, C'), the conventional olive system will become more sustainable, in the overall economic criteria and overall socio-territorial criteria than the organic one. Finally, other changes in the local priorities of main criteria cannot alter the outcome of overall sustainability (Goal) (Figure 6, graph A).

\subsection{Agreement measurement}

Table 2 shows the opinion convergence among the groups of experts which is indicated by the agreement indices/degrees at all nodes, both for the local priorities of the sub-nodes ("Local priorities of nodes") and for the priorities of the alternatives with respect to each node ("Priorities of alternatives"). The RGA index at the "global performance" is medium (c. $3-4, \mathrm{RGA}=10.32$ ). Moreover, there is a slight agreement among the experts regarding these local priorities (Table 2: $\mathrm{c}$. 6-7: RGA index $=4.30$, Agreement degree $=$ low). This low agreement could be explained by the differences in the ideological tendencies of the experts. Regarding the agreement of experts in "priorities of alternatives" with respect to the main criteria, the environmental one is the aspect on which there is more agreement between experts, the agreement degree being medium but at the upper limit of the high agreement index (Table 2: RGA=28.22). The positive environmental impact of organic farming practices is a matter of agreement between several researchers. However, many comparative studies have encountered methodological problems, limiting their ability to draw quantitative conclusions. Thus, there remains a pressing need for longitudinal, system-level stud- 
Table 2 - Agreement in all the nodes of the AHP olive model.

\begin{tabular}{|c|c|c|c|c|}
\hline \multirow{3}{*}{$\begin{array}{l}\text { Nodes of the AHP model } \\
\text { Level } 1 \text { (Goal) } \\
\text { Level 2 (Criteria) }\end{array}$} & \multicolumn{4}{|c|}{ Agreement among experts* } \\
\hline & \multicolumn{2}{|c|}{ Local priorities of nodes } & \multicolumn{2}{|c|}{ Priorities of alternatives } \\
\hline & \multirow{2}{*}{$\begin{array}{l}\text { RGA } \\
\text { Index }\end{array}$} & \multirow{2}{*}{$\begin{array}{l}\text { Agreement } \\
\text { Degree }\end{array}$} & \multirow{2}{*}{$\begin{array}{l}\text { RGA } \\
\text { Index }\end{array}$} & \multirow{2}{*}{$\begin{array}{c}\text { Agreement } \\
\text { Degree }\end{array}$} \\
\hline Level 3 (Subcriteria) & & & & \\
\hline (Column number) & 1 & 2 & 3 & 4 \\
\hline Global performances & 4.3 & • & 10.32 & $\bullet$ \\
\hline I. Economic objectives & 5.04 & • & 7.11 & - \\
\hline I.1. Income & $\mathrm{n} / \mathrm{a}$ & $\mathrm{n} / \mathrm{a}$ & 5.08 & - \\
\hline I.2. Income stability & $\mathrm{n} / \mathrm{a}$ & $\mathrm{n} / \mathrm{a}$ & 4.89 & • \\
\hline I.3. Financial Autonomy & $\mathrm{n} / \mathrm{a}$ & $\mathrm{n} / \mathrm{a}$ & 12.04 & .• \\
\hline I.4. Encouragement by subsidies & $\mathrm{n} / \mathrm{a}$ & $\mathrm{n} / \mathrm{a}$ & 22.07 & .• \\
\hline I.5. MarketAccessibility & $\mathrm{n} / \mathrm{a}$ & $\mathrm{n} / \mathrm{a}$ & 7.37 & • \\
\hline II. Socio-territorial objectives & 5.45 & - & 20.15 & .• \\
\hline II.1. Contribution to employment creation & $\mathrm{n} / \mathrm{a}$ & $\mathrm{n} / \mathrm{a}$ & 26.03 & .• \\
\hline II.2. Collective work & $\mathrm{n} / \mathrm{a}$ & $\mathrm{n} / \mathrm{a}$ & 207.67 & $\cdots$ \\
\hline II.3. Compatibility with local socio-cultural values & $\mathrm{n} / \mathrm{a}$ & $\mathrm{n} / \mathrm{a}$ & 16.55 & .• \\
\hline II.4. Work conditions & $\mathrm{n} / \mathrm{a}$ & $\mathrm{n} / \mathrm{a}$ & 264.02 & ... \\
\hline II.5. Supervision rate & $\mathrm{n} / \mathrm{a}$ & $\mathrm{n} / \mathrm{a}$ & 42.72 & 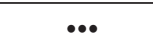 \\
\hline II.6. Qualityapproach & $\mathrm{n} / \mathrm{a}$ & $\mathrm{n} / \mathrm{a}$ & 61.83 & $\ldots$ \\
\hline II.7. Recreational Value of the environnement & $\mathrm{n} / \mathrm{a}$ & $\mathrm{n} / \mathrm{a}$ & 14.74 & •• \\
\hline III. Environmental objectives & 9.62 & • & 28.22 & $\bullet$ \\
\hline III.1. Soilprotection fromerosion & $\mathrm{n} / \mathrm{a}$ & $\mathrm{n} / \mathrm{a}$ & 39.33 & ... \\
\hline III.2. Soilfertility & $\mathrm{n} / \mathrm{a}$ & $\mathrm{n} / \mathrm{a}$ & 257.79 & ... \\
\hline III.3. Water ressources & $\mathrm{n} / \mathrm{a}$ & $\mathrm{n} / \mathrm{a}$ & 37.89 & 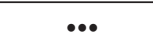 \\
\hline III.4. Minimization of the use of pesticides & $\mathrm{n} / \mathrm{a}$ & $\mathrm{n} / \mathrm{a}$ & 31.79 & 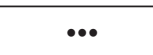 \\
\hline III.5. Biodiversity & $\mathrm{n} / \mathrm{a}$ & $\mathrm{n} / \mathrm{a}$ & 15.82 & $\bullet$ \\
\hline
\end{tabular}

Note: Agreement Degree: $\boldsymbol{\bullet \bullet}=$ High $; \boldsymbol{\bullet}=$ Medium $; \cdot=$ Low. $n / a=$ not applicable because there are no sub-nodes depending on this node. Limits for the segmentation of RGA Indexes: PRGA1/3=10.32; PRGA2/3= 28.22.

ies in order to address these issues and to fill in the gaps in our knowledge of the impacts of organic farming (Hole et al., 2005). Regarding the economic side, it is the aspect for which there is the most difference between experts' opinions (Table 2: c.3: $\mathrm{RGA}=7.11$, Agreement degree=low). The controversy about the economic profitability of organic farming remains. Moreover, Rigby et al. (2001) and Sutherland (2011) have identified low financial rewards as the primary reasons given by organic farmers for reverting to conventional production. In reality, this vision is limited in the short term, since such a positive environmental impact will increase the farming economic viability in the medium-long term. Thereby, the diffusion of sustainable systems must be needed to rethink the cost of the environmental actions.

\section{Discussion}

From an overall sustainability perspective, organic olive growing has proved its superiority. This result is in agreement with the study of Laajimi and Ben Nasr (2009) comparing 
these two olive systems in the same study zone and from a multicriteria point of view based on the IDEA method. This prioritization is also in agreement with previous researches comparing these production systems but under other conditions (Stockdale et al., 2001; Pacini et al., 2003, 2004; Rasul and Thapa, 2004 and Parra-López et al., 2008). This work showed a slightly lower income of organic olive growing system compared to the conventional one. This result is in concordance with the studies of Berentsen et al. (1998), and Lampkin and Padel (1999). Otherwise, Sánchez Jiménez (1999) and Parra-López et al. (2008) obtained a higher income for organic olive farming with respect to conventional methods. These contradictory results can be explained by at least two reasons: I) The context of each study; if it is a research focusing on medium-long term or short-medium term outcomes and II) the characteristics of the study zone such as the socio-economic criteria and the geo-political context. The economic aspect including profitability of sustainable farming is highly criticized in the literature (Schaller, 1993). In Tunisia, the aspects to be improved are mainly related to institutional and policies orientations to support more sustainable agricultural systems. Thus, viability of agriculture may be achieved by adjusting the agricultural behavior to more sustainable practices and through a modulation of decision makers' policies. The improvement of organic olive growing farmers' income seems to be a priority for the importance of this system to preserve the environment. This income can be improved by direct aids or through more sophisticated marketing plans exploring more interesting international markets. In this context, fair trade associated to organic farming can represent a good tool to improve farms' income and can contribute in a best organization of farmers into cooperatives. Certainly, this strategy can contribute to best controlling the value chain and taking advantage of the highest added value of olive oil (Elfkih et al., 2013). On the other hand, knowledge management and information sharing mechanisms can facilitate meaningful participation and promote decision-making at the local level (Mabudafhasi, 2002). Surveyed experts agreed that organic system can provide interesting yields at the short and medium terms always when it is well conducted. So, training and farmers' supervision are essential to go into more sustainable practices and more productive orchards. In the long term, a general consensus was established between scientists, that sustainable farming can generate more productive systems taking into account the soil degradation and water overuse of non sustainable systems. All these assumptions represent an additional motivation to decision makers to provide more support for organic agriculture.

From a consumers' perspective, surveyed experts are in agreement with literature which suggests that consumers are often not well informed about the benefits of organic products essentially in local markets (Vermeir and Verbeke, 2006; Vecchio, 2013; Pomarici et al., 2016). In this context, it was desirable to increase the demand for organic products in the local market by consumer awareness of the importance of organic foods; by setting a clear price policy aiming at the improvement of consumers' purchase capacity and encouraging organic companies and farming to strength the communication of their environmental commitment to consumers through appropriate programs and marketing tools. In fact, from a strategic perspective, supporting sustainable agriculture may be more economically efficient for the state taking into account public expenditure in health. Many studies confirm a positive correlation between pollution and health expenditure, such as the study of Yazdi and Khanalizadeh (2017) which proves that $\mathrm{CO}_{2}$ and $\mathrm{PM}_{10}$ emissions have statistically significant positive effects on health expenditure. Indeed, without a sufficient income, agriculture cannot reach the desirable sustainable levels. For this reason, subsidizing sustainable agriculture is not only the right of farmers but also the right of society and future generations. On the other hand, prices may reflect the real value of products. Fri (1991) argues that markets need the right price signals to work properly, so externalities must be internalized in private markets (Yunlong, 1994).

In relation to the use of the AHP method and the associated software package (Ex- 
pert-Choice), as previously mentioned, AHP has shown a number of strengths and facilities that make it a potentially useful tool in the evaluation of sustainability. The main strengths of AHP realised in this study are: (I) It makes it possible to quantify qualitative, subjective and intangible information, which can be arranged in a complex decision-making problem with high uncertainty and great risk; (II) It makes possible the achievement of an overall aggregated sustainability evaluation; (III) It allows an easy implementation and processing of data via a specific computer support (software "Expert choice"); (IV) It facilitates the identification of the level of agreement between different agents involved in decision making, thus allowing the specification of the preferences of the actors and the necessary justifications; and (V) It provides practical solutions based on a justified choice. On the other hand, the most obvious weaknesses of AHP mentioned in the literature are related to the independence and relevance of objectives, representativeness of the judgments, and open/closed nature of the model. These weaknesses attributed to AHP can be mitigated if the problem is properly structured, as has been implemented in this paper. In addition, the ANP (Analytic Network Process) that is the extension methodology of AHP can be also used if there are many dependent criteria (Ishizaka et al., 2013). In fact, AHP is an effective tool for the sustainability assessment but it is cognitively demanding for the decision makers, and can only embrace a weak sustainability perspective as trade-offs are the norm. The robust results can be obtained with MAUT methodology (Cinelli et al., 2014).

The modeling process is based on a mechanistic agro-ecological engineering approach (Ittersum and Rabbinge, 1997) which makes it possible to deal with specific alternative, technological options or new constraints and policies. This approach is easier than the classical 'empirical' econometric approaches which are based on hard statistical data for certain very restrictive conditions (Janssen and Van Ittersum, 2007). Therefore, this approach seems to be holistic, systemic, integrative and trans-disciplinary. In the olive case study, the use of experts' knowledge is a good option because of the scientific and technical nature of the analyzed criteria. In addition, the discussion of the prototype model with experts is a procedure which has been proven to be a useful concept as the prototype already delivers preliminary results that can be utilized for improvement of the model (Sattler et al., 2010). The validity of our model and results was evaluated through previous partial studies on the impacts of alternatives on the functions of olive growing, as detailed previously. These studies are, in general, narrowly focused on a few functions and impacts, but some of them are more holistic, such as those analyzing the multifunctionality of integrated production (Carmona-Torres et al., 2014).

\section{Conclusions}

This study confirms the global sustainability of the organic production system, as expected by the initial hypothesis. The holistic superiority of the alternative of the olive growing system may be considered as a further reason to foster institutional support to its wider diffusion in Tunisia.

This global sustainability entails contrasts concerning the studied sub-criteria. These contrasts may reveal strengths and weaknesses related to the studied systems, which can contribute to a better orientation of public strategies. Results derived from the AHP evaluation reveal a superiority of the organic olive growing system in all the criteria except for two sub-criteria: economic income (economic criteria) and compatibility with local socio-cultural values (socio-territorial criteria) whereas environmental criteria have demonstrated an overall superiority of all the studied sub-criteria.

In fact, the environmental dimension forms the strong pillar of organic farming, mainly thanks to their diversify advantages: I) It contributes to the maintenance of the organic fertility of the soil. In this context, experts affirm the importance to start with healthy soil to grow healthy food. Nowadays it is widely recognized that organic farming builds up organic soil matter better than conventional systems. In addition, natural cultivation practices are far better than chemical soil 
management; II) Organic farming helps combat serious soil problems such as erosion; III) It contributes to keeping water supplies clean by stopping polluted run-off. In the Sfax region, the majority of organic farmers tend to amend the soil correctly using compost - which helps conserve water; and finally IV) Organic farming encourages biodiversity with intercalary plantation mainly fruit trees in the region of Sfax.

Moreover, organic farming may play an extraordinary social function by adopting an effective innovation process based on an eco-tourism strategy associated to its recreational value. From the socio-territorial point of view, the challenge is how to better sensitize the Tunisian consumer to make of organic olive oil its healthy and ethical choice. This is done by pursuing a strategy aiming to bring the producer closer to the consumer (e.g. through awareness campaigns and publicity) and improving at the same time the consumers' purchase to ameliorate the access to these products. This may make organic products more compatible with local socio-cultural values.

At the economic level, the organic olive growing system has demonstrated great advantages with respect to the conventional system: better stability of the income at the medium and long terms, better financial autonomy, better access to subsidies and better market accessibility through short marketing circuit. Despite all these advantages, the current economic situation (income) presents less performance compared with the conventional one. In other words, organic economic performances are better at the medium and long terms than at the short term. But we cannot insure medium and long term sustainability without a short term viability of this production system. In reality, organic olive farming represents only $2.1 \%$ of agricultural area in the Sfax region where many farmers have given up the organic system for the low registered incomes; which endangers even the existence of this system. The challenge here is how to assist and reinforce the current situation to guarantee the right of future generations in sustainable farming systems, without prejudicing farmers' current economic situation. In this way, three kinds of measures can be suggested:
I) a more oriented prices policy aiming at the internalisation of environmental costs and benefits. This, makes markets more transparent II) subsidising organic farming incomes; actually, specific subsidies for organic farming cover only $70 \%$ of the certification fees (only the five first years of production) and $30 \%$ of agricultural material. This is not enough to make the organic system more preponderant; and III) better information sharing on good cultivation practices to contribute in the improvement of organic yields. In reality, the organic systems present higher production costs caused by lower yields. Therefore, the organic systems should improve their productivity to improve farmers' incomes. Thus, it seems to be obvious that a wider diffusion of organic olive farming in Tunisia would require a combined effort of several actors; decision makers, farmers and scientists; focusing their effort on the improvement of the profitability of the organic farms controlling production costs and improving knowledge management and information sharing mechanisms for a good command of sustainable agricultural practices through direct access to scientific research. Further research is needed to address knowledge and up-take of "green" agricultural practices among both organic and conventional producers outside of agri-environmental schemes, and to rethink the cost of the environmental actions - or lack of - that are being driven by the market (Sutherland, 2011).

Methodologically, the use of MCDM techniques is increasing and providing new analytical tools for the practical resolution of complex problems which are a target in the field of the evaluation of the multifunctionality and sustainability of agriculture. This work contributes to integrating assessment of sustainability of agricultural systems through a well-defined approach from the structuring of the problem - from the setting of the goal to the sensitivity analysis. Through AHP methodology, our study has covered the four integrative elements of integrated assessment: sustainability dimensions, scales, model and stakeholders. The use of the tool comparing experts' judgment has enriched the debate on the agricultural systems sustainability, and reflects the current interest of deci- 
sion-makers in making long-term predictions and simulations of new possible behavior outside the range of observed data.

Finally, this study represents the first step of a wider research project aiming at defining public policies for a wider adoption of more sustainable olive growing systems in Tunisia. Subsequent studies are aimed to complete the vision of the problem: (I) By carrying out a thorough study on production sub-systems which can characterize the production systems already studied; (II) An enrichment of the theoretical approach with other tools, on the one hand, and a reinforcement of the identified advantages of the methodology, on the other hand; (III) greater involvement of farmers and consumers in the information gathering process; (IV) a more integrative analysis taking into account the other components of sustainability, such as the impact of agricultural practices on the multiple agricultural functions; (V) a more in-depth study multiplying existing agricultural systems such as intensive and hyper-intensive olive-growing systems recently introduced in Tunisia.

\section{Acknowledgements}

Thanks go to the Olive Tree Institute of Tunisia that has supported this work. Comments raised by the referees and the editor are highly appreciated. Thanks are also given to Wanderlust International Language Center of Tunisia for its English editing.

\section{References}

Ben Abdallah S., 2015. Evaluation comparative de la multifonctionnalité des systèmes de production oléicole dans la région de Sfax. Master's thesis in Institut National Agronomique de Tunisie, Tunisie, 119 pp. [In French].

Berentsen P.B.M., Giesen G.W.J. and Schneiders M.M.F.H., 1998. Conversion from conventional to biological dairy farming: economic and environmental consequences at farm level. Biological Agriculture and Horticulture, 16 (1998): 311-328.

Bezlepkina I. and Reidsma P., 2011. Integrated assessment of sustainability of agricultural systems and land use: Methods, tools and applications. Agricultural Systems, 104(2): 105-109.
Binder C.R., Feola G. and Steinberger J.K., 2010. Considering the normative, systemic and procedural dimensions in indicator-based sustainability assessments in agriculture. Environmental Impact Assessment Review, 30(2): 71-81.

Callieris R., Roma R. and Brahim S., 2016. Different consumer behaviours for organic food in Tunisia. A cluster analysis application. New Medit, 15(2): 53-62.

Carmona-Torres C., Parra-López C., HinojosaRodríguez A. and Sayadi S., 2014. Farm-level multifunctionality associated with farming techniques in olive growing: An integrated modeling approach. Agricultural Systems, 127: 97-114.

Carof M., Colomb B. and Aveline A., 2013. A guide for choosing the most appropriate method for multi-criteria assessment of agricultural systems according to decision-makers' expectations. Agricultural Systems, 115: 51-62.

Cinelli M., Coles S.R. and Kirwan K., 2014. Analysis of the potentials of multi criteria decision analysis methods to conduct sustainability assessment. Ecological Indicators, 46: 138-148.

Delate K., Duffy M., Chase C., Holste A., Friedrich H. and Wantate N., 2003. An economic comparison of organic and conventional grain crops in a longterm agroecological research (LTAR) site in Iowa. American Journal of Alternative Agriculture, 18(2): 59-69.

Elfkih S., Wannessi O. and Mtimet N., 2013. Le commerce équitable entre principes et réalisations : le cas du secteur oléicole Tunisien. New Medit, 12(1): 13-21.

Elfkih S., Guidara I. and Mtimet N., 2012. Are Tunisian organic olive growing farms sustainable? An adapted IDEA approach analysis. Spanish Journal of Agricultural Research, 10(4): 877-889.

Forman E. and Selly M.A., 2001. Decisions by Objectives. Amazon Edition, 401 pp.

Fri R.W., 1991. Sustainable development: principles into practice. Resources, 102 (1991): 1-3.

Gómez-Limón J.A. and Arriaza-Balmón M., 2011. Evaluación de la sostenibilidad de las explotaciones de olivar en Andalucía. XIII Premio Unicaja de Investigación Agraria, https://www.unicaja.es/ resources/1320671483909.pdf.

Gomez Sal A. and Gonzalez Garcia A., 2007. A comprehensive assessment of multifunctional agricultural land-use systems in Spain using a multi-dimensional evaluative model. Agriculture, Ecosystems \& Environment, 120(1): 82-91.

Hansen B, Alrøe H.F. and Kristensen E.S., 2001. Approaches to assess the environmental impact of or- 
ganic farming with particular regard to Denmark. Agriculture, Ecosystems \& Environment, 83(1-2): 11-26.

Hole D.G., Perkins A.J., Wilson J.D., Alexander I.H., Grice P.V. and Evans A.D., 2005. Does organic farming benefit biodiversity? Biological Conservation, 122(1): 113-130.

Ishizaka A. and Labib A., 2009. Analytic Hierarchy Process and Expert Choice: Benefits and Limitations. OR Insight, 22(4): 201-220.

Ishizaka A. and Nemery P., 2013. Multi-Criteria Decision Analysis Methods and Software. Portsmouth Business School, University of Portsmouth, UK.

Ittersum V.M.K. and Rabbinge R., 1997. Concepts in production ecology for analysis and quantification of agricultural input-output combinations. Field Crops Research, 52 (3): 197-208.

Janssen S. and Ittersum M.K.V., 2007. Assessing farm innovations and responses to policies: Areview of bio-economic farm models. Agricultural Systems, 94(3): 622-636.

Kanter D.R., Musumba M., Wood S.L.R., Palm C., Antle J., Balvanera P., Dale V.H., Hvlik P., Kline K.L., Scholes R.J., Thornton P., Tittonell P. and Andelman S., 2016. Evaluating agricultural trade-offs in the age of sustainable development. Agricultural Systems, http://dx.doi.org/10.1016/j.agsy.2016.09.010.

Laajimi A. and Ben Nasr J., 2009. Appréciation et comparaison de la durabilité des exploitations agricoles biologiques et conventionnelles en Tunisie: cas de l'oléiculture dans la région de Sfax. New Medit, 3(1): 10-19.

Lampkin N. and Padel S., 1994. The Economics of Organic Farming. CAB International, Wallingford.

Mabudafhasi R., 2002. The role of knowledge management and information sharing incapacity building for sustainable development - an example from South Africa. Ocean \& Coastal Management, 45(910): 695-707.

Pacini C., Wossink A., Giesen G., Vazzana C. and Huirne R., 2003. Evaluation of sustainability of organic, integrated and conventional farming systems: a farm and field- scale analysis. Agriculture, Ecosystems \& Environment, 95(1): 273-288.

Pacini C., Wossink A., Giesen G. and Huirne R., 2004. Ecological-economic modelling to support multi-objective policy making: a farming systems approach implemented for Tuscany. Agriculture, Ecosystems \& Environment, 102(3): 349-364.

Parra-López C., Calatrava-Requena J. and de-Haro-Giménez T., 2007. A multi-criteria evaluation of the environmental performances of conventional, organic and integrated olive-growing systems in the south of Spain based on experts' knowledge. Renewable Agriculture and Food Systems, 22(3): 189-203.

Parra-López C., Calatrava-Requena J. and de-Haro-Giménez T., 2008. A systemic comparative assessment of the multifunctional performance of alternative olive systems in Spain within an AHP-extended framework. Ecological Economics, 64(4): 820-834.

Pazek K., Rozman C., Majkovic D., Turk J., Kljaji M., Skraba A., Borec A., Simonic P. and Prisenk J., 2014. Assessment of multifunctional agriculture: application of selected multi-criteria methods in case of Slovenia. Bulgarian Journal of Agricultural Science, 20(5): 1008-1017.

Pomarici E., Amato M. and Vecchio R., 2016. Environmental Friendly Wines: A Consumer Segmentation Study. Agriculture and Agricultural Science Procedia, 8 (2016): 534-541.

Rasul G. and Thapa G.B., 2004. Sustainability of ecological and conventional agricultural systems in Bangladesh: an assessment based on environmental, economic and social perspectives. Agricultural Systems, 79 (2004): 327-351.

Regulation (EC) No 834/2007. Council Regulation (EC) No. 834/2007 of 28 June 2007 on organic production and labelling of organic products and repealing Regulation (EEC) No. 2092/91. Official Journal of the European Union, L 189/1.

Regulation (EC) No 537/2009. Commission Regulation (EC) No 537/2009 of 19 June 2009. Official Journal of the European Union, L 159/6.

Rigby D. and Cáceres D., 2001. Organic farming and the sustainability of agricultural systems. Agricultural Systems, 68(1): 21-40.

Rivals P., 1961. Regards sur les Oliviers de la Région de Sfax. Journal d'agriculture tropicale et de botanique appliquée, 8(4): 203-205.

Saaty T.L., 1980. The Analytic Hierarchy Process. New York: McGraw-Hill.

Saaty T.L., 1994. Fundamentals of Decision Making and Priority Theory with the Analytic Hierarchy Process, AHP Series, Vol. VI. Pittsburgh: RWS Publications.

Saaty T.L., 2001. Decision Making with Dependence and Feedback: The Analytic Network Process. Pittsburgh, USA: RWS Publications.

Sánchez Jiménez S., 1999. El control de costes en el cultivo del olivar. PhD dissertation, Dept. of Business Administration, University of Jaen, Spain.

Sattler C., Nagel U.J., Werner A. and Zander P., 2010. Integrated assessment of agricultural production practices to enhance sustainable development in agricultural landscapes. Ecological Indicators, 10(1): 49-61. 
Schaller N., 1993. The concept of agricultural sustainability. Agriculture, Ecosystems \& Environment, 46(1-4): 89-97.

Stockdale E.A., Lampkin N.H., Hovi M., Keatinge R., Lennartsson E.K.M., Macdonald D.W., Padel S., Tattersall F.H., Wolfe M.S. and Watson C.A., 2001. Agronomic and environmental implications of organic farming systems Advances in Agronomy, 70 (2001): 261-262.

Stolze M., Piorr A., Häring A. and Dabbert S., 2000. The environmental impact of organic farming in Europe. Organic Farming in Europe: Economics and Policy 6. Stuttgart-Hohenheim, Germany.

Sutherland L.A., 2011. "Effectively organic": Environmental gains on conventional farms through the market? Land Use Policy, 28(4): 815-824.

Tunisian Regulation $N^{0} 99-30$ of 5 April 1999. Loi $n^{\circ}$ 99-30 du 5 avril 1999, relative à l'agriculture biologique. Journal Officiel de la République Tunisienne, 29.
Tuomisto H.L., Hodge I.D., Riordan P. and Macdonald D.W., 2012. Does organic farming reduce environmental impacts? A meta-analysis of European research. Journal of Environmental Management, 112: 309-320.

Vecchio R., 2013. Determinants of willingness-topay for sustainable wine: Evidence from experimental auctions. Wine Economics and Policy, 2: 85-92.

Vermeir I. and Verbeke W., 2006. Sustainable food consumption: Exploring the consumer "attitudebehavioral intention" gap. Journal of Agricultural and Environmental Ethics, 19(2): 169-194.

Yazdi S.K. and Khanalizadeh B., 2017. Air pollution, economic growth and health care expenditure. Journal of Economic Research-Ekonomska Istrazivanja, 30(1): 1181-1190.

Yunlong C. and Smit B., 1994. Sustainability in agriculture: a general review. Agriculture, Ecosystems \& Environment, 49: 299-307. 